\title{
Reduction of deltaic channel mobility by tidal action under rising
}

\section{relative sea level}

\author{
Nathan Lentsch ${ }^{1 *}$, Alvise Finotello ${ }^{2}$, and Chris Paola ${ }^{1}$ \\ ${ }^{1}$ St. Anthony Falls Laboratory, Department of Earth Sciences, University of Minnesota, Minneapolis, Minnesota 55414, USA \\ Department of Geosciences, University of Padova, via G.Gradenigo 6, Padova 35131, Italy
}

\begin{abstract}
As Holocene river deltas continue to experience sea-level rise, sediment carried by distributary channels counteracts delta-plain drowning. Many deltas worldwide are subject to tidal action, which strongly affects the morphology of distributary channels and could also influence their mobility. Here we show, through physical laboratory experiments, that distributary-channel mobility can be dramatically reduced in systems affected by tides in comparison to an identical system with no tides, and that the mobility of distributary channels decreases as the ratio of tidal to fluvial energy increases. This effect occurs even if new accommodation space is created by rising relative sea level. By analyzing synthetic stratigraphy derived from both digital elevation data and time-lapse photography, we show also that the reduction of channel mobility in tidal deltas increases channel stacking and connectivity in the stratigraphic record.
\end{abstract}

\section{INTRODUCTION}

Deltaic environments support productive coastal ecosystems and large human populations, with the tide-influenced megadeltas of Asia (e.g., the Ganges-Brahmaputra, Mekong, Changjiang, etc.) alone hosting over 200 million humans (Goodbred and Saito, 2012) Addressing how these tidally influenced deltas (TIDs) respond morphologically to rising relative sea level (RSL) is therefore critical for managing the evolving landscape and the population it supports (Jerolmack, 2009; Syvitski et al., 2009; Giosan et al., 2014). Since the fundamental work of Galloway (1975), the effect of tides on delta morphology has been extensively explored (Olariu and Bhattacharya, 2006; Tänavsuu-Milkeviciene and Plink-Björklund, 2009; Geleynse et al., 2011; Goodbred and Saito, 2012; Plink-Björklund, 2012; Sassi et al., 2012; Shaw and Mohrig, 2014; Rossi et al., 2016; Hoitink and Jay, 2016; Hoitink et al., 2017). Recent studies demonstrate how tides prevent mouth-bar growth at distributarychannel outlets (Rossi et al., 2016), effectively stabilizing distributary channels and reducing their number, while promoting channel lengthening seaward and sediment bypass through deltaic plains (Olariu and Bhattacharya, 2006; Syvitski and Saito, 2007; Shaw and Mohrig, 2014; Rossi et al., 2016). Does such stabilization persist in the face of rising RSL, and if so, how is it recorded in deltaic strata? Changes in RSL exert a dominant control on the evolution

*Current address: ExxonMobil Exploration Company, 22777 Springwood Village Parkway, Spring, Texas 77389, USA of distributary-channel networks, and therefore deltas, by creating new accommodation space and promoting aggradation and channel avulsion (Jerolmack, 2009; Martin et al., 2009). Because most of the world's largest deltas are currently sinking due to oil and gas extraction, groundwater withdrawal, and mean sea-level rise induced by global climate changes (Syvitski et al., 2009; Hoitink et al., 2017), it is crucial to understand how TIDs function in the face of rising RSL. Given that centuries are needed for delta morphologies to adapt to rapid changes (Hoitink et al., 2017), the study of modern deltas provides only a limited snapshot view. The stratigraphic record provides time-integrated information, but few clear examples of ancient TIDs have been recognized in the field (PlinkBjörklund, 2012). Key morphological indicators, such as tidal mouth bars and funnel-shaped tidal channels, are not readily identifiable in the rock record (Dalrymple and Choi, 2007). Physical experiments (Paola et al., 2009; Kleinhans et al., 2015) offer an additional source of insight and allow for the study of processes, such as distributary-channel mobility, at a temporal and spatial resolution that is impractical in the field (Martin et al., 2009; Van Dijk et al., 2009; Ganti et al., 2016). Here we present the results of experiments carried out at Saint Anthony Falls Laboratory (SAFL; University of Minnesota, USA) to investigate how tidal forcing affects the morphodynamic and stratigraphic evolution of deltas under RSL rise conditions. Specifically, we combine data from time-lapse photography and high-resolution digital elevation models (DEMs) and, by varying the ratio of total tidal to fluvial energy, we assess how tides influence both the mobility of distributary channels and the stratigraphy of the deltaic deposit.

\section{APPROACH}

We conducted a series of delta experiments at SAFL in a $5 \times 5 \times 0.5 \mathrm{~m}$ basin that allows for continuously varying water and sediment inputs, and programmable changes in base level. The latter is regulated via an electrically operated weir, while sediment and water are supplied by a computer-controlled point source in one corner of the basin. The basin can also reproduce sinuous tides via two industrial pumps connecting the main basin to an auxiliary basin. The parameters of the three delta experiments we analyze here are reported in Figure 1A. Further information on the experimental setup, as well as on supplemental experiments, can be found in the GSA Data Repository ${ }^{1}$ (Fig. DR1 and Table DR1). Prior to each experiment, we grew an approximately uniform 2-m-radius delta using walnut-shell sand (particle size distribution $\mathrm{D}_{50}$ $\sim 320 \mu \mathrm{m})$ that, owing to its low density (1350 $\mathrm{kg} / \mathrm{m}^{3}$ ), can be easily entrained and deposited by both tidal and fluvial currents (Baumgardner, 2015). Then, we imposed a steady RSL rise rate that continued for the whole experiment. Sediment and water discharges were set to keep pace with base-level rise, maintaining a constant delta-topset area. To isolate the effects of tides on distributary-channel mobility, base-level rise, as well as sediment and water discharge, were kept constant, while tide parameters varied for each experiment (Fig. 1A). The tidal period and amplitude were chosen to satisfy the following criteria: (1) long enough to provide a quasisteady reversing flow, but (2) shorter than the time scale of substantial change in the delta channel network ( $\sim \mathrm{h}$ ), while (3) able to move sediment on both flood and ebb phases of the tidal cycle. We did not otherwise attempt to scale the tides or other parameters to any particular system (Paola et al., 2009; Kleinhans et al., 2014).

Data were collected by means of overhead time-lapse imaging, taken every $3 \mathrm{~min}$ for

${ }^{1}$ GSA Data Repository item 2018207, experimental methods, time-lapse experiment videos, aspect ratio pdf, and shoreline positions, is available online at http://www.geosociety.org/datarepository/2018/, or on request from editing@geosociety.org. 

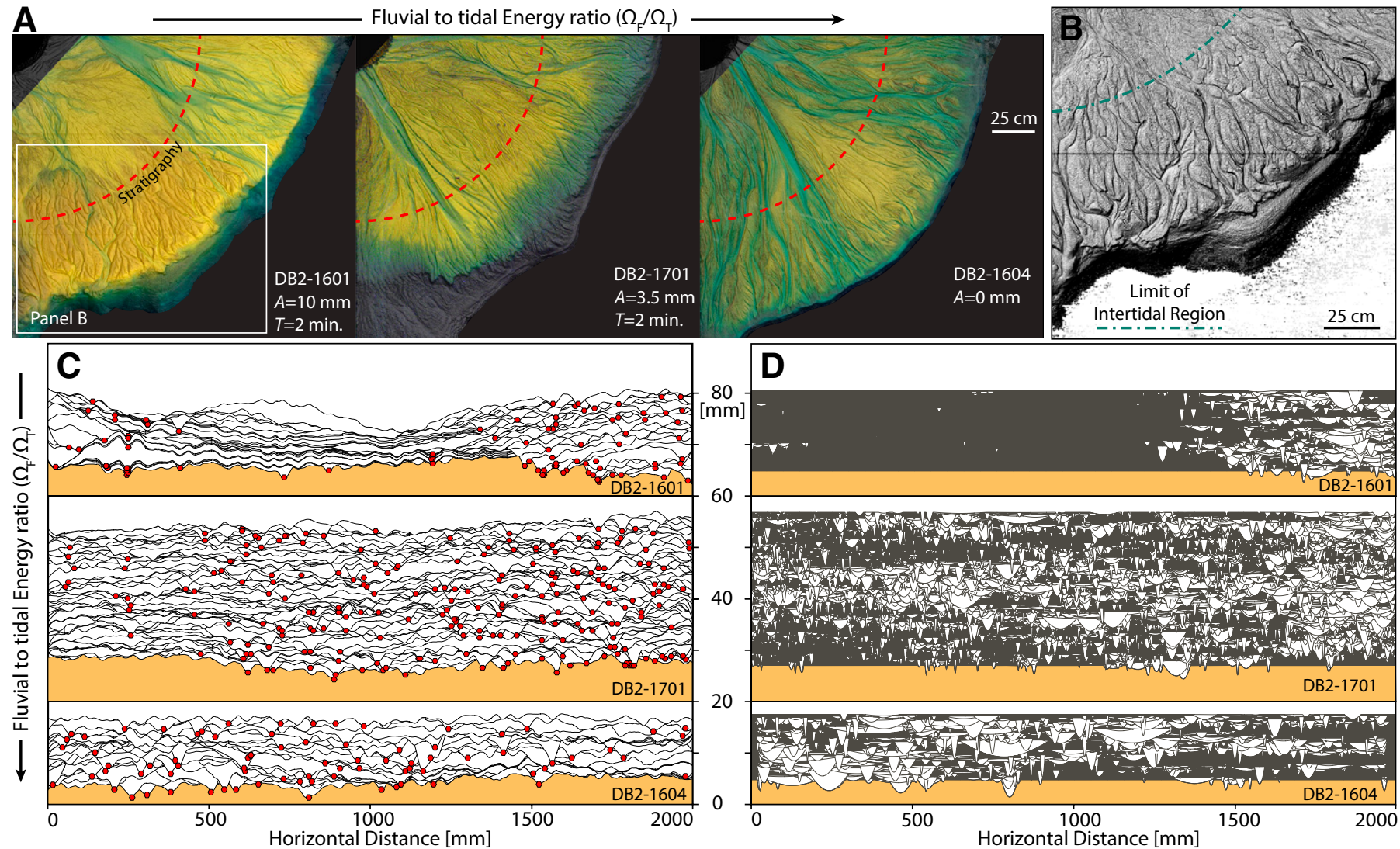

60

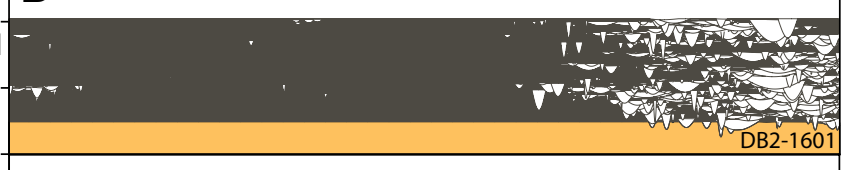

40

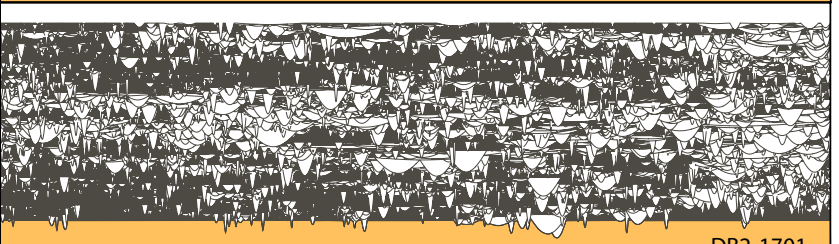

DB2-1701

Figure 1. A: Overhead images of the three experiments reported here superimposed on the corresponding hill-shaded digital elevation model (DEM) data. All images were taken at the midpoint of the experiment. Dashed lines indicate transect location for the generated synthetic stratigraphy. Tidal amplitude $(A)$ and period $(T)$ for each experiment are also reported. All experiments have the same relative sea level (RSL) rise rate $(0.5 \mathrm{~mm} / \mathrm{hr})$, water discharge $\left(Q_{\mathrm{w}}=5.0 \times 10^{-5} \mathrm{~m}^{3} / \mathrm{s}\right)$ and sediment discharge $\left(Q_{\mathrm{s}}=5.0 \times 10^{-7} \mathrm{~m}^{3} / \mathrm{s}\right)$. B: Close-up view of the headwardgrowing tidal channels observed in experiment DB2-1601. C: Synthetic stratigraphy obtained from hourly DEM scans. Subsequent scans clip all previous, higher elevation data to account for erosion. All topographic profiles were smoothed using a Savitzky-Golay filter with a window size of $50 \mathrm{~mm}$. Channel thalwegs, represented by red dots, were identified by thresholding local minima of the profile curvature. Experiment DB2-1701 shows a larger cross section, as it was allowed to aggrade for longer. D: Synthetic stratigraphy generated from wet/dry maps derived from overhead photographs. Each horizon depicts channel locations every 6 min. The depths depicted here were assigned from the probability distributions of channel width-to-depth ratio measured from wet/dry maps and DEM data, respectively. Subsequent horizons clip higher elevations to account for erosion.

experiment DB2-1601 and $1 \mathrm{~min}$ for DB2-1604 and DB2-1701, and high-resolution $(<1 \mathrm{~mm}$ vertical, $1 \mathrm{~mm}$ horizontal) topographic scans (DEMs), taken every hour. Dyed water allowed us to create binary maps of wet and dry regions based on HSV (hue, saturation, value) color thresholds (Wickert et al., 2013), from which we found the location of active channels. To measure the influence of tides on the mobility of deltaic distributary channels, we measured individual pixel changes in wet/dry state between sequential images (Wickert et al., 2013; Baumgardner, 2015). We normalized the total number of state changes by the number of common pixels in two consecutive maps to give a state change fraction, which is then divided by the time step between images to compute the state change fraction per time. We used mean state change fraction per time $(\bar{M})$ to compare channel mobility between experiments.

Additionally, in order to identify the stratigraphic signature of changes in channel mobility, we used two different methods to create synthetic stratigraphy along a transect located just outside the intertidal zone (Fig. 1A). The first method relies on the stacking of DEM data. To identify channels, we filtered DEMs using a Savitzki-Golay filter to reduce noise. The filter has a window of 50 data points $(50 \mathrm{~mm})$ and its coefficients are specified by a $2^{\text {nd }}$ degree polynomial via unweighted linear least-squares regression. We plot filtered elevation data along the transect for each hourly scan, clipping previous profiles wherever the new elevation is lower (i.e., previous topography is eroded) (Fig. 1C). While the DEM data, which were acquired on an hourly basis, adequately captures overall change in delta morphology, they cannot track minor modifications. Therefore, we developed a second methodology for creating synthetic stratigraphy based on active-channel location derived from the wet/ dry maps. Because the entire system experiences uniform base-level rise, the time step between images can be easily converted to a mean elevation change. Therefore, channels can be stacked in a way similar to the DEM process, except that the channel depth is not known. Therefore, we superimposed every DEM scan with the image corresponding to the nearest time step, allowing for measurements of channel width $(B)$ and depth $(h)$ from wet/dry images and DEM data, respectively. To account for potential variation of aspect ratio $(\beta=B / h)$, for a given channel width $B_{0}{ }^{*}$, we classified active channels into width bins (bin increment $=10 \mathrm{~mm}$, and widths in the range $0<B<300 \mathrm{~mm}$ ) and calculated, for each bin, an empirical distribution function of $h(B)$ (see Fig. DR2) from which we selected a channel depth $\left[h_{0}^{*}=h\left(B_{0}^{*}\right)\right]$ (see the Data Repository for further details). Using the same transect (Fig. 1A), we generated synthetic stratigraphy every 6 min from the images to allow for nine additional horizons each hour as compared to the DEM data (Fig. 1D).

\section{RESULTS AND DISCUSSION}

The synthetic stratigraphy obtained from both the DEM and image-based methods are qualitatively similar (Figs. 1C and 1D), showing 
clear differences in distributary-channel body distribution between systems with varying tidal influence. The stacking density of channel bodies has long been used as an index of channel mobility and avulsion rates, both in the field (Mohrig et al., 2000; Chamberlin and Hajek, 2015), and in physical experiments (Sheets et al., 2007; Hajek et al., 2010). Particularly, higher tidal ranges (experiment DB2-1601) hold the main distributary channel captive in its location throughout the experiment, while small, secondary channels occasionally branch from the main channel to distribute sediment to other portions of the delta (Figs. 1A and 2A); this effect persists in the face of rising RSL, and the stabilization of the main distributary channel is most pronounced for the highest tidal range. The action of tides in delta-plain areas not occupied by active distributary channels leads to the development of tidal channels, growing via headward erosion (D'Alpaos et al., 2005). These tidal channels can extend up to the intertidal zone limit (Fig. 1B) and frequently capture water and sediment load carried by secondary fluvial channels (Fig. 1A).

Conversely, a fluvial delta evolving without tidal forcing (experiment DB2-1604) produces widespread, frequently avulsing distributary channels that effectively distribute sediment across the whole delta topset, thus maintaining a relative static shoreline (see Fig. DR4). The effect of tidal stabilization of channels is clear in the preserved strata: systems with stronger tidal influence display stratigraphy with higher vertical channel connectivity and amalgamation due to decreased avulsion rates (Fig. 1). Particularly, the stratigraphy found in experiment DB2-1601 (Figs. 1C and 1D) shows a concentration of channel bodies on the right side of the transect, while few to no channel bodies are observed on the left and central portion of the transect.

Results for state change fraction per time (Fig. 2) support the stratigraphic analysis and show that the mobility of distributary channels is reduced even in a weakly tide-influenced delta (experiment DB2-1701). Both lateral migration and avulsion frequency drop significantly as tidal strength increases (Fig. 2), leading to slightly higher stacking density compared to the purely fluvial case (Fig. 1).

To compare our results to field cases, we also quantify the relative energy of the tidal and fluvial forcing. We use modified forms of the metrics developed by Baumgardner (2015) to calculate tidal and fluvial energy delivered to the delta per unit time per unit length of shoreline (power/length, $\mathrm{W} / \mathrm{m}$ ). Tidal energy $\left(\Omega_{\mathrm{T}}\right)$ is derived from the height of the tidal prism, $H_{T}$, and the tidal period, $T$, as

$$
\Omega_{\mathrm{T}}=\rho g H_{T}^{3} / S T
$$

where $\rho$ is the density of water, $g$ is gravitational acceleration, and $S$ is the slope of the intertidal

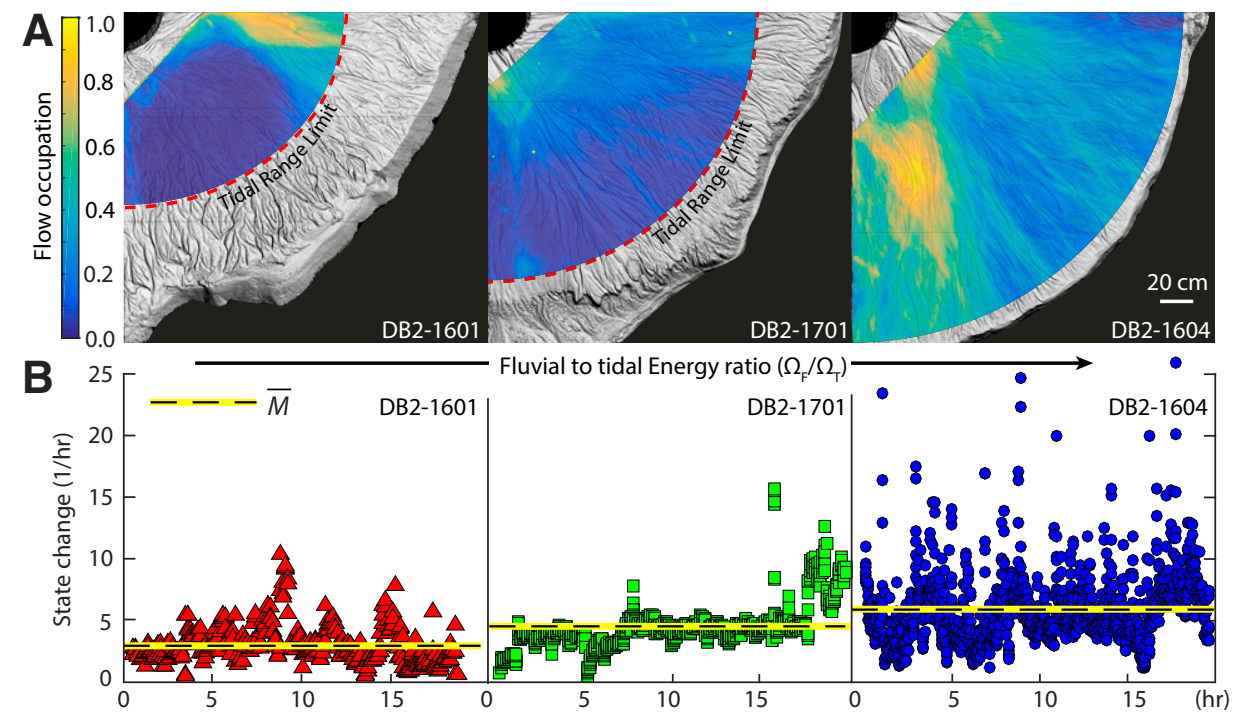

Figure 2. A: Cumulative flow occupation maps for the three analyzed experiments. Yellow denotes continuous flow occupation, and blue denotes areas of no flow occupation. For the experiments involving tides, analysis is limited to the purely fluvial portion of the delta topset. Tidal range limit is highlighted by a dashed red line. B: State change fraction per time versus run time for all three experiments. Each data point represents the change in "wet" and "dry" pixels for consecutive images, which is used here as a proxy for channel mobility. Spikes in the plotted data are associated with avulsions, in which a channel is rapidly abandoned in favor of a new flow path. Mean state change fraction per time $(\bar{M})$ for the entire experiment is also highlighted in yellow. Missing data points for the last $2 \mathrm{~h}$ of experiment DB2-1601 are due to a mechanical failure.

zone. Fluvial energy $\left(\Omega_{\mathrm{F}}\right)$ is derived from channel discharge, $Q$, and slope, $S$, as

$$
\Omega_{\mathrm{F}}=\rho g Q \hat{S h} / C_{\mathrm{f}} L_{s} .
$$

where $\hat{h}$ is a characteristic flow-depth of riverine input $(\sim 10 \mathrm{~mm}), C_{\mathrm{f}}$ is the drag coefficient $(\sim 1.5$ $\times 10^{-3}$ for laminar flow) and $L_{\mathrm{s}}$ is the length of delta shoreline ( 1.9 m; see Fig. DR4).

Comparing the fluvial-to-tidal energy ratio of our experiment with the observed mean state change fraction per time $(\bar{M})$, we see that, overall, the mobility of channels increases as relative tidal energy decreases (Fig. 3). This is primarily due to the ability of the ebb-enhanced flow to keep distributary channels flushed by removing sediments deposited during the previous flood. Rising RSL strengthens this dynamic by enhancing the erosive strength of the current (Canestrelli et al., 2010). This promotes channel deepening (Rossi et al., 2016) and prevents backfilling, reducing avulsion frequency as back-sedimentation is insufficient to produce a topographic gradient advantage (Hoyal and Sheets, 2009; Van Dijk et al., 2009, 2012), while overbank flooding is limited by the higher channel relief (Edmonds et al., 2009).

In the TID experiments, we also observed that smaller secondary channels branching from the main distributaries had their incoming water and sediment load captured by the widespread tidal channels dissecting the most distal portion of the delta plain, thus connecting the tidal and upstream river channels (Fig. 1A). This phenomenon reduces topographic gradients as sediment is more evenly distributed across the delta plain (Fig. 1C), and further inhibits distributary channel avulsions. This effect is likely more pronounced in field-scale TIDs where areas lateral to the active distributaries accrete vertically, potentially keeping pace with rising RSL, due to the interplay of organic and inorganic deposition (Goodbred and Saito, 2012).

Finally, it is worth noting that, in field cases, such as in the Ganges-Brahmaputra-Meghna Delta of Bangladesh (Wilson and Goodbred, 2015), significant onshore transport of fine,

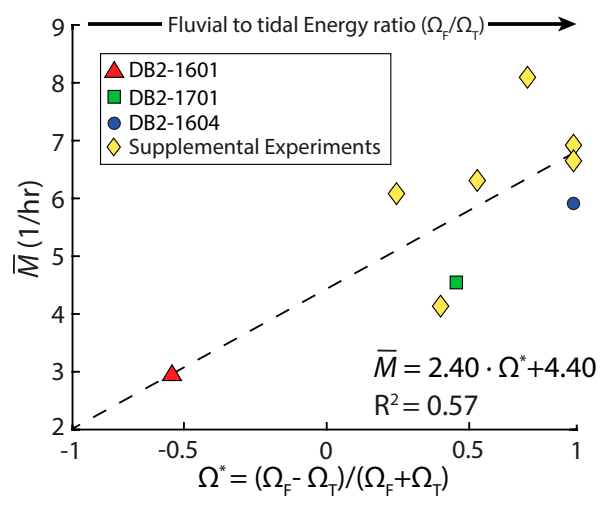

Figure 3. Relative fluvial $\left(\Omega_{\mathrm{F}}\right)$ and tidal $\left(\Omega_{\mathrm{T}}\right)$ energy versus the mean state change fraction per time $(\bar{M})$, here used as a measure of distributary channel mobility. Information on the supplemental experiments can be found in Table DR1 in the Data Repository (see footnote 1). 
cohesive sediments in off-channel areas might further increase channel stability by increasing bank resistance to erosion. Overall, we suggest that the stabilization of channels by tidal action that enhances flushing of bed-material sediment is a general effect that will affect the capacity of the world's deltas to distribute sediment in response to rising RSL.

\section{ACKNOWLEDGMENTS}

This work was supported by the U.S. National Science Foundation (NSF) via the Delta Dynamics Collaboratory (grant EAR-1135427 to Paola); by the BanglaPIRE project, NSF Partnerships for International Research and Education (grant IIA 09-68354 to Paola); by the University of Padova (grant BIRD 168939 to Finotello); and also by the St. Anthony Falls Laboratory Industrial Consortium for Experimental Stratigraphy (Paola). Additionally, the publication of this paper was supported by the ExxonMobil Exploration Company. We are grateful for constructive reviews from M. Kleinhans, S. Goodbred, A. Cantelli, and P. Plink-Björklund, which substantially improved this paper.

\section{REFERENCES CITED}

Baumgardner, S.E., 2015, Quantifying Galloway: Fluvial, tidal and wave influence on experimental and field deltas [Ph.D. thesis]: Minneapolis, University of Minnesota, $113 \mathrm{p}$.

Canestrelli, A., Fagherazzi, S., Defina, A., and Lanzoni, S., 2010, Tidal hydrodynamics and erosional power in the Fly River delta, Papua New Guinea: Journal of Geophysical Research, v. 115, https://doi.org/10.1029/2009JF001355.

Chamberlin, E.P., and Hajek, E.A., 2015, Interpreting paleo-avulsion dynamics from multistory sand bodies: Journal of Sedimentary Research, v. 85 , p. 82-94, https://doi.org/10.2110/jsr.2015.09.

D’Alpaos, A., Lanzoni, S., Marani, M., Fagherazzi, S., and Rinaldo, A., 2005, Tidal network ontogeny: Channel initiation and early development: Journal of Geophysical Research: Earth Surface, v. 110, p. 1-14, https://doi.org/10.1029 /2004JF000182.

Dalrymple, R.W., and Choi, K., 2007, Morphologic and facies trends through the fluvial-marine transition in tide-dominated depositional systems: A schematic framework for environmental and sequence-stratigraphic interpretation: Earth-Science Reviews, v. 81, p. 135-174, https://doi.org /10.1016/j.earscirev.2006.10.002.

Edmonds, D.A., Hoyal, D.C.J.D., Sheets, B.A., and Slingerland, R.L., 2009, Predicting delta avulsions: Implications for coastal wetland restoration: Geology, v. 37, p. 759-762, https://doi.org /10.1130/G25743A.1.

Galloway, W.E., 1975, Process framework for describing the morphological and stratigraphic evolution of deltaic depositional systems, in Broussard, M.L., ed., Deltas: Models for Exploration: Houston, Texas, Houston Geological Society, p. 87-98.

Ganti, V., Chadwick, A.J., Hassenruck-Gudipati, H.J., Fuller, B.M., and Lamb, M.P., 2016, Experimental river delta size set by multiple floods and backwater hydrodynamics: Science Advances, v. 2 , p. e1501768, https://doi.org/10.1126/sciadv 1501768

Geleynse, N., Storms, J.E.A., Walstra, D.J.R., Jagers, H.R.A., Wang, Z.B., and Stive, M.J.F., 2011,
Controls on river delta formation; Insights from numerical modelling: Earth and Planetary Science Letters, v. 302, p. 217-226, https://doi.org /10.1016/j.eps1.2010.12.013.

Giosan, L., Syvitski, J., Constantinescu, S., and Day, J., 2014, Climate change: Protect the world's deltas: Nature, v. 516, p. 31-33, https://doi.org/10 $.1038 / 516031 \mathrm{a}$

Goodbred, S.L.J., and Saito, Y., 2012, Tide-dominated deltas, in Davis, R.A.J., and Dalrymple, R.W., eds., Principles of Tidal Sedimentology: Springer, p. 129-149, https://doi.org/10.1007/978-94-007 -0123-6_7.

Hajek, E.A., Heller, P.L., and Sheets, B.A., 2010, Significance of channel-belt clustering in alluvial basins: Geology, v. 38, p. 535-538, https://doi .org/10.1130/G30783.1.

Hoitink, A.J.F., and Jay, D.A., 2016, Tidal river dynamics: Implications for deltas: Reviews of Geophysics, v. 54, p. 240-272, https://doi.org/10.1002 /2015RG000507.

Hoitink, A.J.F., Wang, Z.B., Vermeulen, B., Huismans, Y., and Kästner, K., 2017, Tidal controls on river delta morphology: Nature Geoscience, v. 10, p. 637-645, https://doi.org/10.1038/ngeo3000.

Hoyal, D.C.J.D., and Sheets, B.A., 2009, Morphodynamic evolution of experimental cohesive deltas: Journal of Geophysical Research: Earth Surface, v. 114, p. 1-18, https://doi.org/10.1029 /2007JF000882.

Jerolmack, D.J., 2009, Conceptual framework for assessing the response of delta channel networks to Holocene sea level rise: Quaternary Science Reviews, v. 28, p. 1786-1800, https://doi.org/10 $.1016 /$ j.quascirev.2009.02.015.

Kleinhans, M.G., et al., 2014, Quantifiable effectiveness of experimental scaling of river- and delta morphodynamics and stratigraphy: Earth-Science Reviews, v. 133, p. 43-61, https://doi.org /10.1016/j.earscirev.2014.03.001.

Kleinhans, M.G., Van Scheltinga, R.T., Van Der Vegt, M., and Markies, H., 2015, Turning the tide: Growth and dynamics of a tidal basin: Journal of Geophysical Research: Earth Surface, v. 120, p. 95-119, https://doi.org/10.1002 /2014JF003127.

Martin, J., Sheets, B., Paola, C., and Hoyal, D., 2009, Influence of steady base-level rise on channel mobility, shoreline migration, and scaling properties of a cohesive experimental delta: Journal of Geophysical Research: Solid Earth, v. 114, F03017, https://doi.org/10.1029/2008JF001142.

Mohrig, D., Heller, P.L., and Lyons, W.J., 2000, Interpreting avulsion process from ancient alluvial sequences: Guadalope-Matarranya system (northern Spain) and Wasatch Formation (western Colorado): Geological Society of America Bulletin, v. 112, p. 1787-1803, https://doi.org/10.1130 /0016-7606(2000)112<1787:IAPFAA>2.0.CO;2.

Olariu, C., and Bhattacharya, J.P., 2006, Terminal distributary channels and delta front architecture of river-dominated delta systems: Journal of Sedimentary Research, v. 76, p. 212-233, https://doi .org/10.2110/jsr.2006.026.

Paola, C., Straub, K., Mohrig, D., and Reinhardt, L., 2009, The "unreasonable effectiveness" of stratigraphic and geomorphic experiments: Earth-Science Reviews, v. 97, p. 1-43, https://doi.org/10 $.1016 /$ j.earscirev.2009.05.003.

Plink-Björklund, P., 2012, Effects of tides on deltaic deposition: Causes and responses: Sedimentary
Geology, v. 279, p. 107-133, https://doi.org/10 $.1016 /$ j.sedgeo.2011.07.006.

Rossi, V.M., Kim, W., López, J.L., Edmonds, D., Geleynse, N., Olariu, C., Steel, R.J., Hiatt, M., and Passalacqua, P., 2016, Impact of tidal currents on delta-channel deepening, stratigraphic architecture, and sediment bypass beyond the shoreline: Geology, v. 44, p. 927-930, https://doi.org/10 1130/G38334.1.

Sassi, M.G., Hoitink, A.J.F., De Brye, B., and Deleersnijder, E., 2012, Downstream hydraulic geometry of a tidally influenced river delta: Journal of Geophysical Research, v. 117, https://doi.org/10 1029/2012JF002448.

Shaw, J.B., and Mohrig, D., 2014, The importance of erosion in distributary channel network growth, Wax Lake Delta, Louisiana, USA: Geology, v. 42, p. 31-34, https://doi.org/10.1130/G34751.1.

Sheets, B.A., Paola, C., and Kelberer, J.M., 2007, Creation and preservation of channel-form sand bodies in an experimental alluvial system, in Nichols, G., et al., eds., Sedimentary Processes, Environments and Basins, Oxford, UK, Blackwell, p. 555-567, https://doi.org/10.1002/9781444304411 .ch22.

Syvitski, J.P.M., Kettner, A.J., Overeem, I., Hutton, E.W.H., Hannon, M.T., Brakenridge, G.R., Day, J., Vörösmarty, C., Saito, Y., Giosan, L., and Nicholls, R.J., 2009, Sinking deltas due to human activities: Nature Geoscience, v. 2, p. 681-686, https://doi.org/10.1038/ngeo629.

Syvitski, J.P.M., and Saito, Y., 2007, Morphodynamics of deltas under the influence of humans: Global and Planetary Change, v. 57, p. 261-282, https:// doi.org/10.1016/j.gloplacha.2006.12.001.

Tänavsuu-Milkeviciene, K., and Plink-Björklund, P., 2009, Recognizing tide-dominated versus tideinfluenced deltas: Middle Devonian strata of the Baltic Basin: Journal of Sedimentary Research, v. 79 , p. $887-905$, https://doi.org/10.2110/jsr .2009 .096 .

Van Dijk, M., Kleinhans, M.G., Postma, G., and Kraal, E., 2012, Contrasting morphodynamics in alluvial fans and fan deltas: Effect of the downstream boundary: Sedimentology, v. 59, p. 2125 2145, https://doi.org/10.1111/j.1365-3091.2012 .01337.x.

Van Dijk, M., Postma, G., and Kleinhans, M.G., 2009, Autocyclic behaviour of fan deltas: An analogue experimental study: Sedimentology, v. 56, p. 1569-1589, https://doi.org/10.1111/j.1365 $-3091.2008 .01047 . x$.

Wickert, A.D., Martin, J.M., Tal, M., Kim, W., Sheets, B., and Paola, C., 2013, River channel lateral mobility: Metrics, time scales, and controls: Journal of Geophysical Research: Earth Surface, v. 118, p. 396-412, https://doi.org/10.1029 12012JF002386

Wilson, C.A., and Goodbred, S.L., Jr., 2015, Construction and maintenance of the Ganges-BrahmaputraMeghna Delta: Linking process, morphology, and stratigraphy: Annual Review of Marine Science, v. 7, p. $67-88$, https://doi.org/10.1146/annurev -marine-010213-135032.

Manuscript received 24 July 2017

Revised manuscript received 10 May 2018

Manuscript accepted 12 May 2018

Printed in USA 